\title{
Article \\ Sustainability Awareness of In-Service Physical Education Teachers
}

\author{
Salvador Baena-Morales ${ }^{1}\left(\mathbb{D}\right.$, Alberto Ferriz-Valero ${ }^{1, * \mathbb{C}}$, Javier Campillo-Sánchez ${ }^{2} \mathbb{D}$ and \\ Sixto González-Víllora ${ }^{3}[$ ()
}

1 EDUCAPHYS Research Group, Department of General and Specifics Didactics, University of Alicante, 03690 Alicante, Spain; salvador.baena@ua.es

2 Sports Councillor of the Santomera Town Council, 30140 Santomera, Spain; javicampillo86@gmail.com

3 Department of Physical Education, Arts Education and Music, Faculty of Education, Universidad de Castilla-La Mancha, 02071 Albacete, Spain; sixto.gonzalez@uclm.es

* Correspondence: alberto.ferriz@ua.es

Citation: Baena-Morales, S.;

Ferriz-Valero, A.; Campillo-Sánchez, J.; González-Víllora, S. Sustainability Awareness of In-Service Physical Education Teachers. Educ. Sci. 2021, 11, 798. https://doi.org/10.3390/ educsci11120798

Academic Editor: Athanasios Mogias

Received: 28 October 2021

Accepted: 3 December 2021

Published: 7 December 2021

Publisher's Note: MDPI stays neutral with regard to jurisdictional claims in published maps and institutional affiliations.

Copyright: (c) 2021 by the authors. Licensee MDPI, Basel, Switzerland. This article is an open access article distributed under the terms and conditions of the Creative Commons Attribution (CC BY) license (https:// creativecommons.org/licenses/by/ $4.0 /)$.

\begin{abstract}
Physical Education has been described as a subject with unique characteristics that can contribute to achieving Sustainable Development Goals. However, an analysis of PE teachers' (PETs) sustainability consciousness has not yet been conducted. For this purpose, a total of 203 PETs completed the validated SCQ-S instrument to measure the three dimensions of sustainable development in three components of consciousness (attitudes, knowledge and behaviours). The results obtained show that the PETs have a high consciousness for sustainable development (SD), except for attitudes within the economic dimension. Sex has been identified as a variable that determines awareness in sustainability with significantly higher scores for women in all the variables evaluated, except for knowledge and behaviour in the social dimension. These findings provide new knowledge within the Physical Education and SD paradigm, serving as a link for future research that aims to harness the benefits of Physical Education for the sustainability of the planet.
\end{abstract}

Keywords: education; sustainable development; Sustainable Development Goals; teacher training; consciousness

\section{Introduction}

"Climate change is widespread, rapid and intensifying", begins the global report of the Intergovernmental Panel on Climate Change [1]. This recent international report differs from previous reports on the vital importance of immediate action to avoid future climate disasters as it points out that the consequences of climate change are irreversible. The consequences of what is happening today can only be reduced in 20 years if radical and immediate action is undertaken. This bleak future points to a global temperature increase of more than four degrees Celsius and the emergence of significant climate disruptions in all regions of the world without exception [2]. Another conclusion presented in the document is the irrefutable anthropogenic origin of this environmental crisis, which means that the increase in greenhouse gases in the atmosphere has been unequivocally caused by human activity [3-5]. However, this environmental crisis entails ecological problems and a series of socio-economic consequences, such as increased crime, social inequality, migration, and economic imbalances between social classes. This has led not only to an environmental conception of SD but also to the integration of social and economic issues into this overall sustainability strategy $[6,7]$.

This global problem has meant that, for years, the leading intergovernmental institutions have been trying to establish a series of strategies that allow for the sustainable development (SD) of the planet. The SD concept was proposed more than three decades ago by the Brundtland Commission and understood as moderation in the use of the resources the planet offers but without jeopardising the needs of future generations [8]. Within the 
strategies that seek an SD of the planet, two proposals have been highlighted. The first was the development of the Millennium Development Goals (MDGs), which consisted of eight goals that sought to achieve SD mainly in developing countries [9]. Fifteen years later, another broader and more ambitious proposal was established, known as the SD Goals (SDGs) [10]. This international campaign consists of 17 goals that apply to the entire population of the planet and aim to be achieved by 2030. Specifically, SDGs are, in turn, divided into 169 specific targets that help to concretise the actions that favour the balanced development of the planet which are then grouped into three main dimensions of sustainability: (i) environmental, (ii) social and (iii) economic [11]. Consequently, SD has become a relevant concept for policymakers worldwide, highlighting a clear and unified message that only with everyone's help can the sustainability of the planet be achieved.

As can be seen, in order to achieve SDGs, planned, well-structured actions adapted to the possibilities of each individual are required. Within this framework for action, education plays a leading role, leading to the emergence of a specific term, Education for SD (ESD) [12,13]. The justification for this importance is clear: only through education can present and future generations be made aware of how to achieve SDGs. For this reason, ESD has covered a broad theoretical and scientific framework over the last six years, reaching a series of conclusions on how it can contribute to the improvement of $\mathrm{SD}$. One worth mentioning is the importance of teacher awareness and training, which is highlighted by the following statement: "educators are powerful agents of change, who can provide the educational response needed to achieve SDGs" [12] (p. 51). It is also emphasised that it is not enough to train teachers, but that teachers' beliefs and practices are fundamental to ensuring the progress and sustainability of the planet [14]. Therefore, in order to achieve a more sustainable world, the sustainability issues described in SDGs must be addressed in education, and the education community (teachers and learners) must become agents of change. Nevertheless, this is only possible if the different actions, such as learning and teaching of content, development of competencies and utilisation of methods, are dealt with in a specialised and subject-conscious manner. Therefore, it is necessary to consider the actions that promote SD as a crucial issue, which should not only be dealt with in a transversal way with generic or isolated actions but in a specific way according to the scope of each educational discipline.

\subsection{Why Promote the SDGs through Physical Education?}

ESD indicates the great potential of all school subjects to promote SD. This interdisciplinary character is one of its main strengths. In the specific case of Physical Education, it seems to possess a series of intrinsic characteristics that allows it to contribute to sustainability through its three main dimensions and the SDGs (environmental, social and economic) [15-17]. Following this line of thinking, 169 targets of SDGs were analysed and 26 were selected that could have a greater benefit when approached from the Physical Education area. Although this study paradigm focused on the SD and Physical Education binomial is still in an "embryonic phase" at a practical level, the theoretical assumptions found in previous literature seem to confirm that Physical Education improves environmental, social, and economic aspects [18] (Figure 1).

For example, concerning the environmental dimension, the characteristics of Physical Education facilitate the creation of an ideal context to promote environmental care [19-21]. This is achieved through actions such as promoting active commuting to school and working on sports content in natural environments such as orienteering or climbing, complemented by transversal activities in natural environments. Second, under the social aspect, Physical Education has traditionally been considered a fundamental element in promoting social justice [22], recognised as capable of creating egalitarian educational contexts that favour participation and cooperation [23,24]. Finally, in response to the contribution to the economic dimension, it is apparent that a student population that is more adherent to the practice of daily physical exercise is related to savings for the public health system, both in terms of visits to doctors and in the use of drugs, which in turn 
contribute to a more significant expulsion of greenhouse gases by the pharmacological industry $[25,26]$.

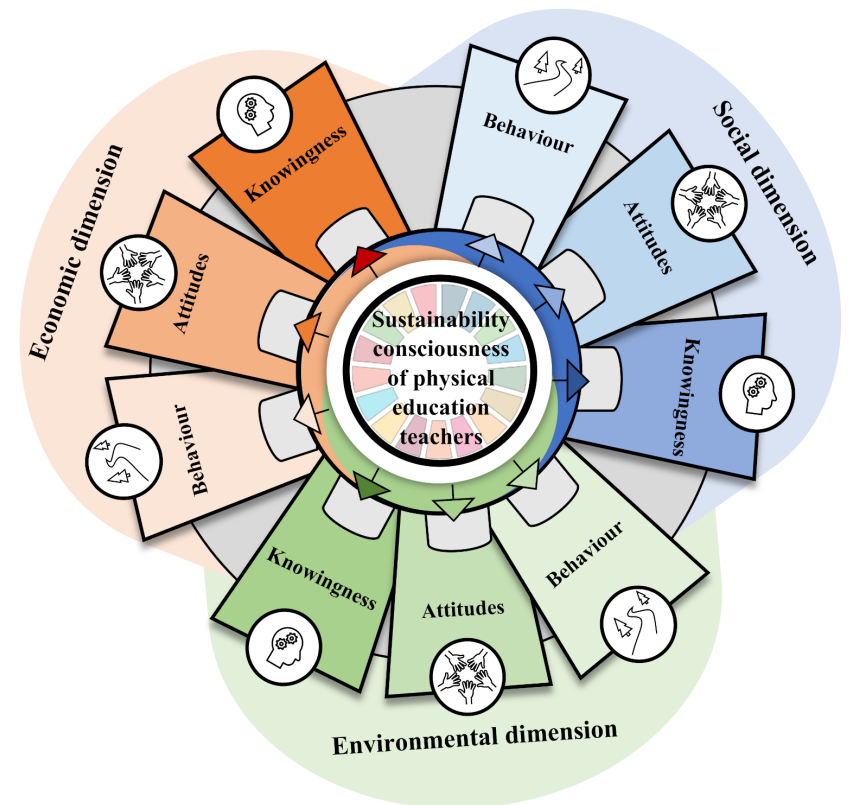

Figure 1. Relationship between the three dimensions of SD and the components of sustainability consciousness.

PETs, from their training at university, must maintain feedback with society. They should be involved in social problems, set trends and show, through knowledge and practice, what needs to be done to achieve the sustainability of human systems [27]. In all educational settings, educators can help learners understand the complex decisions necessary for SD and motivate them to transform society and themselves. In order to guide and empower the student body, educators must be trained and equipped with the knowledge, skills, values and behaviours required for this transition [28]. Such an endeavour necessitates the improvement of both initial education and lifelong learning of PETs [29]

For this, it is necessary to make improvements in both initial education and permanent education of physical education teachers [29]. Many of these improvements must adhere to policies regarding quality Physical Education (QPE) and ensure that their contributions will improve aspects of sustainable development [16]. QPE implies a planned, progressive, inclusive learning experience that forms part of the curriculum in early years, primary and secondary education. In this respect, QPE acts as the foundation for lifelong engagement in physical activity and sport. The learning experience offered to children and young people through physical education lessons should be developmentally appropriate to help them acquire the psychomotor skills, cognitive understanding, and social and emotional skills they need to lead a physically active life [29]. Unifying criteria in this sense will facilitate an increase in the quality and quantity of data, and a common measurement framework will allow interested parties to obtain information on where and how to intervene. In this process, in order to multiply the results and for Physical Education to act as leverage policy, it will also be essential to improve the horizontal coherence of these policies, with particular relevance given to the formation of alliances and the exchange of experiences between public administrations, universities, schools, etc. [30]. It is also essential that new studies and practical knowledge from the world of academia are provided in this regard. It is no longer a question of whether Physical Education can be a tool to support the 2030 Agenda but how it can be maximised. Indeed, the primary goal is to optimise and expand the application and impact of its initiatives [28]. The Commonwealth Secretariat [31] has been working, taking the Kazan Action Plan [17] as a reference, on this policy coherence 
through a proposal of indicators at the global level to check and measure the contribution of Physical Education and sports on the different prioritised goals within the broader SDGs. Within this proposal, the elements of this global Action Plan that are most directly related to the purpose of this study are listed in Table 1.

Table 1. Example of a proposal for an indicator in Physical Education and its relationship with the global goals and indicators of the 2030 Agenda.

\begin{tabular}{|c|c|c|}
\hline \multicolumn{2}{|c|}{ Global Target and Indicator of the 2030 Agenda } & $\begin{array}{c}\text { Associated Indicator } \\
\text { Proposal }\end{array}$ \\
\hline $\begin{array}{l}\text { Target 4.7: By 2030, ensure that all } \\
\text { students acquire the knowledge } \\
\text { and skills necessary to promote } \\
\text { SD, including through ESD and } \\
\text { sustainable lifestyles, human } \\
\text { rights, equality of sex, the } \\
\text { promotion of a culture of peace } \\
\text { and non-violence, world } \\
\text { citizenship and the appreciation } \\
\text { of cultural diversity and the } \\
\text { contribution of culture to SD. }\end{array}$ & $\begin{array}{l}\text { (a) national policies; } \\
\text { (b) study plans and } \\
\text { programs; } \\
\text { (c) teacher training; } \\
\text { (d) student evaluation. }\end{array}$ & $\begin{array}{l}\text { Percentage of schools } \\
\text { claiming to provide } \\
\text { quality physical education } \\
\text { in whole or in part as } \\
\text { defined by UNESCO's } \\
\text { Guide for Policymakers on } \\
\text { Quality Physical } \\
\text { Education. }\end{array}$ \\
\hline
\end{tabular}

Within this global context, we are specifically evaluating behaviours in sustainability by PETs, which must be conceived as a fundamental element to assess their knowledge and attitudes about SD. These behaviours will significantly condition their leadership ability to promote quality Physical Education that promotes sustainable lifestyles. Thus, the main challenge we face is to resolve existing deficiencies with determination. We must take advantage of the strengths and opportunities that sports present us and create concrete and viable projects framed in the sustainability and Quality Physical Education strategies defined in the short, medium, and long term [32].

In addition to all this evidence, how the 'sex' variable can influence the analysis of teachers' and students' sustainability awareness should be considered. In this sense, Lozano and Figueredo [33] pointed out the importance of analysing sex roles to examine sustainability awareness within a more precise framework. Previous literature indicates that women have a higher degree of awareness of SD improvement [34-37]. However, no previous work has been found that analyses potential sex differences in in-service PETs.

\subsection{The Aim and Context of the Study and Research Questions}

Despite these promising features in the Physical Education paradigm for SD, the analysis of previous literature shows several weaknesses that need to be addressed. There is a lack of research assessing the level of sustainability awareness of PETs. This type of research is fundamental since these teachers work in an ideal context to contribute to a minimum of 26 out of 169 specific targets that make up SDGs [18]. Therefore, the aim of this research was to describe the levels of sustainability consciousness of secondary school PETs. For this purpose, the three levels of consciousness (knowingness, attitudes, and behaviour) and the three dimensions of sustainability (environmental, social and economic) were explored. In addition, the influence of sex on the obtained results was also explored since previous literature has documented it as a variable that could produce significant differences between the samples studied. Therefore, this research hypothesised (H1) that PETs might have a high awareness of SD. Furthermore, it is necessary to study the behaviour of the sex variable since female teachers seem to have a higher awareness of sustainability than males [38]. Thus, a second hypothesis (H2) was proposed, which argued that female PETs would have a greater awareness of sustainability than males. 


\section{Materials and Methods}

\subsection{Participants and Data Collection}

The questionnaire was completed by 203 PETs in secondary and high school education (122 males and 81 females). The mean age of the participants was $41.2 \pm 12.5$. Regarding the academic level taught by the teachers, several grades were structured, resulting in a total distribution in secondary school teachers as follows: 113 taught in the first cycle (first, second and third grade), 40 in the second cycle (fourth grade) and 50 in high school. Regarding the type of school, 89.66 were in a state school, 7.39 in a state-subsidised school and 2.96 in a private school. All participants belonged to the same region of Spain (Andalusia), acknowledged being in-service during the questionnaire and had at least three years of experience as a teacher.

Given the difficulty of collecting data in the exceptional circumstances of the COVID19 pandemic, the PETs were asked to complete questionnaire through a link created on Google Forms. A total of 463 surveys were distributed ( $43.84 \%$ response rate), which were distributed through a convenience sampling procedure. Ethical aspects were respected in accordance with the regulations of the authors' university (UA-2020-09-02); the participants were informed of the objective of the study, as well as its voluntary character and the anonymity and confidentiality of the information provided. The PETs had to confirm that they were in-service teachers for their responses to be accepted. All participants provided their written consent for the scientific dissemination of the data. The questionnaire was disseminated through different educational institutions, encouraging them to share it with other colleagues. Data collection occurred over a span of four weeks (15 January to 31 May 2021). The research was based on responses from a sample of in-service PETs, both public and private, who teach lessons. We cannot rule out the possibility of selection bias. However, several factors favour the representativeness of the sample; for example, no significant differences were perceived between individuals who responded immediately to the survey and those who responded after several reminders. In addition, the characteristics of the surveyed academics adequately represent those of the population as a whole in terms of characteristics such as gender or field of education.

\subsection{Instrument}

The instrument used to measure the sustainability awareness of PETs was the short version of the Sustainability Consciousness Questionnaire (SCQ-S) [39]. This instrument consists of 27 items that are divided into nine sections. On the first level, the three components of consciousness, which are knowledge (items K1-K9), attitudes (items A1-A9) and behaviour (items B1-B9), are analysed with each level of consciousness divided into three items. At the same time, each section is also divided in order to cover the three dimensions of SD (environment, society and economy). This allows the knowledge, attitudes, and behaviour within each dimension of sustainability of the PETs to be measured. The questionnaire's responses are composed of a five-point Likert scale ranging from 1 "strongly disagree" to 5 "strongly agree". The 27 items of the SCQ-S are formulated with the UNESCO framework as a theoretical basis and cover almost the entire spectrum of 15 sub-themes that make up SD, except for two: theme 6 (HIV/AIDS, as these items were considered to be within the sub-theme of health) and theme 10 (rural development) [38]. In addition, SCQ-S is adequate for use as a reference questionnaire due to its optimal reliability and validity values. The results presented by the authors show a Cronbach's alpha above 0.70 for each of the three components of sustainability awareness: sustainability knowingness $(\alpha=0.70)$, sustainability attitudes $(\alpha=0.78)$ and sustainability behaviour $(\alpha=0.72)$. The results of the factor analysis showed that the SCQ items, translated into Spanish, could be modelled on three latent factors corresponding to sustainability knowledge. The three constructs were reliable according to Cronbach's $\alpha$ which was always higher than 0.6 , being higher than 0.7 in the case of sustainability knowledge and sustainability attitudes. 


\subsection{Data Analysis}

The SPSS 24.0 statistics software was used to carry out all the analyses. Each factor's descriptive statistics (mean and standard deviation) were calculated. Kolmogorov-Smirnov's normality test was performed, obtaining non-normal distributions in all cases $(p<0.05)$. To analyse differences between men and women, a Mann-Whitney $U$ test was carried out. The effect size was also calculated using Microsoft Excel software [38]. This magnitude was regarded as small when values ranged between 0.1 and 0.3 , medium between 0.3 and 0.5 and large if greater than 0.5 [40-42]. According to Faul et al. [43], the statistical power of the sample size was calculated using the free software $G^{*}$ Power (see 3.1.9.6, University of Dusseldorf, Germany). The sample size of 122 men and 81 women with an estimated medium effect size (0.5) and a significance of $95 \%$ resulted in a power of 0.94 . Finally, to interpret the Spearman range correlation coefficient used to analyse the degree of association between measurement variables, the following criteria were adopted: less than 0.1 (trivial), $0.1-0.3$ (small), 0.3-0.5 (moderate), 0.5-0.7 (large), 0.7-0.9 (very large) and 0.9-1.0 (almost perfect; [44]).

\section{Results}

\subsection{Descriptive Analysis}

The obtained descriptive results are presented as the mean and standard deviation (SD) for each questionnaire item. The three dimensions of sustainability, as well as the three types of consciousness for each dimension, are shown in Table 2.

Table 2. Descriptive analysis for the 27 items of the SCQ-S in in-service PETs.

\begin{tabular}{|c|c|c|c|c|}
\hline Items & & & Mean & SD \\
\hline & \multicolumn{4}{|c|}{ Sustainability knowingness $(\alpha=0.70)$} \\
\hline 1 & \multirow{3}{*}{ Environmental } & Reducing water consumption is necessary for SD. & 3.62 & 1.12 \\
\hline 2 & & $\begin{array}{c}\text { Preserving the variety of living creatures is necessary for SD (preserving } \\
\text { biological diversity). }\end{array}$ & 4.41 & 0.61 \\
\hline 3 & & $\begin{array}{c}\text { For SD, people need to be educated in how to protect themselves against } \\
\text { natural disasters. }\end{array}$ & 4.13 & 0.77 \\
\hline 4 & \multirow{3}{*}{ Social } & $\begin{array}{l}\text { A culture where conflicts are resolved peacefully through discussion is necessary } \\
\text { for SD. }\end{array}$ & 4.38 & 0.63 \\
\hline 5 & & Respecting human rights is necessary for SD. & 4.34 & 0.66 \\
\hline 6 & & To achieve SD, all the people in the world must have access to good education. & 4.39 & 0.64 \\
\hline 7 & \multirow{3}{*}{ Economic } & $\begin{array}{c}\text { SD requires that companies act responsibly towards their employees, customers, } \\
\text { and suppliers. }\end{array}$ & 4.37 & 0.57 \\
\hline 8 & & SD requires a fair distribution of goods and services among people in the world. & 4.36 & 0.63 \\
\hline 9 & & Wiping out poverty in the world is necessary for SD. & 4.3 & 0.62 \\
\hline \multicolumn{5}{|c|}{ Sustainability attitudes $(\alpha=0.78)$} \\
\hline 10 & \multirow{3}{*}{ Environmental } & $\begin{array}{l}\text { I think that using more natural resources than we need does not threaten the health } \\
\text { and well-being of people in the future. }\end{array}$ & 4.4 & 0.62 \\
\hline 11 & & I think that we need stricter laws and regulations to protect the environment. & 4.41 & 0.63 \\
\hline 12 & & $\begin{array}{c}\text { I think that it is important to take measures against problems that have to do with } \\
\text { climate change. }\end{array}$ & 4.43 & 0.59 \\
\hline 13 & \multirow{3}{*}{ Social } & $\begin{array}{l}\text { I think that everyone ought to be given the opportunity to acquire the knowledge, } \\
\text { values and skills that are necessary to live sustainably. }\end{array}$ & 4.44 & 0.58 \\
\hline 14 & & $\begin{array}{l}\text { I think that we who are living now should make sure that people in the future } \\
\text { enjoy the same quality of life as we do today. }\end{array}$ & 4.46 & 0.63 \\
\hline 15 & & $\begin{array}{l}\text { I think that women and men throughout the world must be given the same } \\
\text { opportunities for education and employment. }\end{array}$ & 4.41 & 0.59 \\
\hline 16 & \multirow{3}{*}{ Economic } & $\begin{array}{l}\text { I think that companies have a responsibility to reduce the use of packaging and } \\
\text { disposable articles. }\end{array}$ & 4.38 & 0.59 \\
\hline 17 & & I think it is important to reduce poverty. & 4.39 & 0.66 \\
\hline 18 & & $\begin{array}{l}\text { I think that companies in rich countries should give employees in poor nations the } \\
\text { same conditions as in rich countries. }\end{array}$ & 4.38 & 0.58 \\
\hline
\end{tabular}


Table 2. Cont.

\begin{tabular}{|c|c|c|c|c|}
\hline Items & & & Mean & SD \\
\hline & \multicolumn{4}{|c|}{ Sustainability behaviour $(\alpha=0.72)$} \\
\hline 19 & \multirow{3}{*}{ Environmental } & I recycle as much as I can. & 3.66 & 1.07 \\
\hline 20 & & $\begin{array}{c}\text { I always separate food waste before putting out the rubbish when I have } \\
\text { the chance. }\end{array}$ & 3.79 & 1.01 \\
\hline 21 & & $\begin{array}{l}\text { I have changed my personal lifestyle in order to reduce waste (e.g., throwing away } \\
\text { less food or not wasting materials). }\end{array}$ & 3.69 & 1.07 \\
\hline 22 & \multirow{3}{*}{ Social } & $\begin{array}{l}\text { When I use a computer or mobile to chat, to text, to play games and so on, I always } \\
\text { treat others as respectfully as I would in real life. }\end{array}$ & 4.85 & 0.36 \\
\hline 23 & & I support an aid organisation or environmental group. & 3.14 & 1.40 \\
\hline 24 & & I show the same respect to men and women, boys and girls. & 4.89 & 0.32 \\
\hline 25 & \multirow{3}{*}{ Economic } & \multirow{3}{*}{$\begin{array}{l}\text { I do things which help poor people. } \\
\text { I often purchase second-hand goods over the internet or in a shop. } \\
\text { I avoid buying goods from companies with a bad reputation for looking after their } \\
\text { employees and the environment. }\end{array}$} & 2.97 & 1.39 \\
\hline 26 & & & 3.07 & 1.42 \\
\hline 27 & & & 3.11 & 1.28 \\
\hline
\end{tabular}

As presented in Figure 2, the items assessing sustainability behaviour had the lowest scores for all three dimensions of SD, and specifically, economic behaviour had the lowest average score $(3.05 / 5)$.

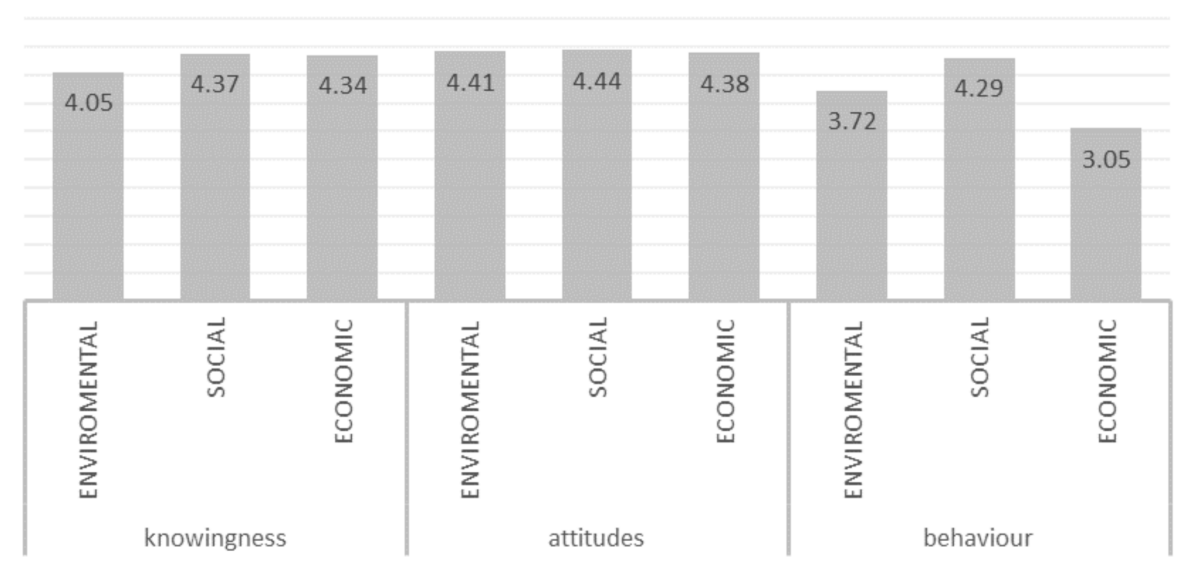

Figure 2. Bar diagram showing the means for each of the dimensions and components of sustainability consciousness.

3.2. Descriptive and Comparative Analysis for Sex with the Dimensions of SD and the Components of Sustainability Consciousness

The descriptive analysis according to sex showed higher scores in the SCQ-S questionnaire for female PETs in all the sustainability consciousness variables that were assessed (Table 3). The inexistence of normality in the items that made up the dimensions, together with their ordinal nature, required the use of non-parametric techniques to assess the significance of these differences. The inferential analysis using the Mann-Whitney U test showed significant differences $(p \leq 0.05)$ in all variables, except those relating to knowledge and behaviour in the social dimension (Table 3). The effect size was small in all cases. 
Table 3. Mean and standard deviation for the sex variable according to dimensions and components of sustainability consciousness.

\begin{tabular}{|c|c|c|c|c|c|c|c|}
\hline & & \multirow{2}{*}{ Men } & \multirow{2}{*}{ Women } & \multicolumn{2}{|c|}{ Mann-Whitney U test } & \multirow{2}{*}{ ES } & \multirow{2}{*}{ Interpretation } \\
\hline & & & & $\mathrm{Z}$ & SIG. & & \\
\hline \multirow{3}{*}{ Knowingness } & ENV & $3.95 \pm 0.50$ & $4.22 \pm 0.39$ & -3.319 & 0.001 & 0.23 & Small \\
\hline & SOC & $4.32 \pm 0.45$ & $4.46 \pm 0.29$ & -1.425 & - & - & - \\
\hline & ECO & $4.29 \pm 0.39$ & $4.43 \pm 0.29$ & -2.115 & 0.034 & 0.14 & Small \\
\hline \multirow{3}{*}{ Attitudes } & ENV & $4.35 \pm 0.40$ & $4.52 \pm 0.27$ & -2.669 & 0.008 & 0.18 & Small \\
\hline & SOC & $4.36 \pm 0.41$ & $4.57 \pm 0.32$ & -3.054 & 0.002 & 0.21 & Small \\
\hline & $\mathrm{ECO}$ & $4.33 \pm 0.45$ & $4.48 \pm 0.27$ & -1.983 & 0.047 & 0.13 & Small \\
\hline \multirow{3}{*}{ Behaviour } & ENV & $3.54 \pm 0.63$ & $4.01 \pm 0.49$ & -1.983 & 0.001 & 0.13 & Small \\
\hline & SOC & $4.25 \pm 0.53$ & $4.37 \pm 0.48$ & -1.386 & - & - & - \\
\hline & $\mathrm{ECO}$ & $2.92 \pm 0.78$ & $3.26 \pm 0.73$ & -2.626 & 0.009 & 0.18 & Small \\
\hline
\end{tabular}

ENV: Environmental; SOC: Social; ECO: Economical; Grouping variable: Sex; ES = Effect size.

\section{Discussion}

The aim of this study was to describe and compare the level of sustainability awareness of in-service PETs in a region of southern Spain, assessing attitudes, knowledge, and behaviour in the three dimensions of SD. The results show that the PETs have high sustainability awareness values for most of the dimensions assessed, except for the behaviour in the economic dimension for which the descriptive analysis shows lower scores. Physical Education has characteristics that suggest that the PETs could have a high awareness of $\mathrm{SD}$, and this hypothesis (H1) was accepted after the analyses were carried out. In addition, this study also suggested that female PETs might have a higher awareness of sustainability than males. Significant differences were found in most of the variables, with female PET scores being higher than male PET scores in all cases (Table 1). Therefore, this hypothesis (H2) is also confirmed in the population assessed.

This original research contributes to broadening the knowledge framework surrounding the Physical Education and SD binomial. The importance of this relationship is justified because Physical Education has been shown to be a subject that could contribute significantly to the achievement of SDGs proposed by the United Nations $[15,17,18]$. However, studies aimed at assessing the awareness for SD of PETs are almost non-existent [45].

Regarding the first hypothesis of the study, the results show that PETs reported high scores for knowledge and attitude in sustainability in its three dimensions. These results coincide with those presented by other scientific works in which the SCQ-S was also assessed in educational settings. For example, Marcos-Merino et al. [46] studied Spanish primary school teachers in training and noted their high level of attitudes towards sustainability for all three dimensions of SD, especially in the social aspects. The same authors reported that the lowest scores were related to economic behaviour, such as buying second-hand products or avoiding companies who have a bad reputation for not taking care of the environment. With a higher score but coinciding with the work of MarcosMerino et al. [46], it was also detected that PETs do not have a particular involvement with non-governmental organisations working on social or environmental needs. On the other hand, Gericke et al. [39] found a decrease in scores for behavioural items in all three dimensions of SD among Swedish 18- and 19-year-olds. Within the behaviour in the social dimension, for example, item 24, which relates to gender equality (SDG 5), relates to item 22 (respect in digital communication) since they are the only ones that received scores close to five points.

As there is no precedent in the scientific literature comparing the sustainability awareness of PETs, it is difficult to further justify these results without abusing speculation. However, taking research focused on trainee teachers as reference, these results could be because teachers seem to prioritise the acquisition of knowledge, skills and practices related to SD to the detriment of other types of learning, such as the promotion of ethical values or positive attitudes towards sustainability [47]. 
Despite these coincidences with previous literature, some disagreements should be mentioned. In recent qualitative research, it was highlighted that PETs had little knowledge of the scope of SD as they understood it mainly as an environmental issue, thus overlooking other dimensions such as the social and economic ones [45]. This fact seems to contradict the results of this research; however, if the SCQ-S items are carefully analysed concerning knowledge of SD (items 1-9), it is observed that these questions represent a series of actions with logical consequences that could improve SD of the planet in its three dimensions. In this line of discussion, it could be inferred that the PETs established high scores in these SCQ-S items because of their coherence of the question asked. On the other hand, when asked in a general way and without specifying actions that favour SD, teachers' real knowledge does not seem to be so broad [18] Regarding this difference in knowledge about sustainability, Ull et al. [48] pointed out that trainee teachers are not aware of the daily activities that can cause damage to the environment.

On the other hand, the second objective of this research was to analyse the differences between men and women concerning sustainability awareness of PETs. The results show significant differences for the population studied in all the assessed variables, except for those relating to knowledge and behaviour in the social dimension. Moreover, women PETs received a higher score in all the items of the questionnaire. This fact justifies the result obtained by Olsson and Gericke [49] where a sex gap was pointed out for sustainability awareness, both overall and in the three separate dimensions of SD. Furthermore, the research conducted with Swedish students highlighted that this gap would increase with the age of the students. In a similar vein, Martín-Ezpeleta and Echegoyen-Sanz [38] found that females showed significantly higher sensitivity to sustainability-related values and behaviours than males. Additionally, Lozano and Figueredo [33] showed that women are more sensitive to sustainability-related values and behaviours. This assertion has also been verified by older studies [50], indicating that female students have a more favourable attitude towards nature than males. This hypothesis regarding a higher level of sustainability awareness among women would also fall within the proposal of Gifford and Sussman [51] who considered that the profile of an individual with a higher level of sustainability awareness would be a woman, young and upper-middle-class. Part of this explanation could be defended by Bogner and Wiseman [52] who showed that women registered a greater awareness for the protection of nature and its care. In this study, men also scored higher on actions that would imply a modification of nature if it could meet the needs of humans.

Despite these coincidences, some disagreements with previous literature should be mentioned. For example, several researchers have found no differences in sustainability awareness for sex [53-55]. However, these works are exclusively focused on the environmental dimension of SD. On the other hand, Marcos-Merino et al. [46] detected sex differences to a lesser extent, specifically those related to sustainability behaviour; the authors found scores to be more significant in male participants, especially in the economic dimension. Another case is found in the work of Baena-Morales el al., [56] where the self-perceived eco-sustainable digital competence of male teachers was higher than that of female teachers at the same teaching stage.

Some limitations of the present study should be acknowledged. First, it should be noted that there is little previous literature that measures sustainability consciousness in in-service teachers in general and in Physical Education in particular, which made it difficult to discuss the results. Another limitation is that the SCQ-S questionnaire is validated for assessing all the themes proposed by UNESCO for SD, except for theme 10 (rural development), and we should be aware that this aspect has not been examined in the present research. Therefore, SCQ-S presents several base problems, for example: (a) It is easy for everyone to answer "strongly agree" with every statement regardless of what he/she actually knows and how he/she actually behaves. (b) Sustainability is a very open concept, and all participants may have very different representations. (c) Each dimension may include many different aspects that cannot be represented by just three items per 
dimension. Finally, it should be acknowledged that the sample used belongs to a specific region of southern Spain (Andalusia). In addition, the sampling procedure was conducted on the convenience of sampling, and thus the results obtained cannot be extrapolated to other populations. This fact should encourage future researchers to repeat similar studies, taking data from different regions of Spain and comparing them. In addition, this future research could examine other variables such as educational level, income, attendance at environmental education programmes and sustainability literacy, among others.

\section{Conclusions}

This research study is the first to assess the sustainability awareness of in-service PETs. The results show that, in general, the PETs have a high awareness of SD in its three dimensions, except for attitudes in the economic dimension. The gender of the PETs is a variable that conditions sustainability consciousness; however, this factor should be studied in greater depth. Women obtained higher scores in all the items of the questionnaire evaluated; therefore, when designing training and awareness-raising programmes on SDGs, it is necessary to focus more on methodological strategies for men to adopt a more sustainable awareness for the planet. As far as possible, these behaviours should be developed so that the results are similar to those of women. Finally, a series of shortcomings were detected in the sustainability consciousness of the PETs that should be further investigated as there is a gap between knowledge and attitudes concerning behaviour that favours SD, with the latter receiving lower scores from the PETs.

Author Contributions: The author S.B.-M. had the idea for the study, drafted it and general supervised. Conceptualization, S.B.-M., S.G.-V. and A.F.-V.; formal analysis, S.B.-M. and A.F.-V.; drafted conclusions, S.B.-M., S.G.-V., J.C.-S. and A.F.-V.; writing-review and editing, S.B.-M. and A.F.-V.; visualization, S.B.-M.; supervision, S.B.-M., S.G.-V. and A.F.-V. All authors have read and agreed to the published version of the manuscript.

Funding: This research was supported by Consejo Superior de Deportes (Spain) under Grant 20/UPB / 21-Research Network for the Promotion of Equality and Physical Activity in Education (RIPIAFE).

Institutional Review Board Statement: The study was conducted according to the guidelines of the Declaration of Helsinki, and approved by the Institutional Review Board (UA-2020-09-02).

Informed Consent Statement: Informed consent was obtained from all subjects involved in the study.

Conflicts of Interest: The authors declare no conflict of interest.

\section{References}

1. IPCC. AR6 Climate Change 2021: Impacts, Adaptation and Vulnerability. Available online: https://www.ipcc.ch/report/sixthassessment-report-working-group-ii/ (accessed on 20 October 2021).

2. WWA Western North American Extreme Heat Virtually Impossible without Human-Caused Climate Change. Available online: https:/ /www.worldweatherattribution.org/western-north-american-extreme-heat-virtually-impossible-without-humancaused-climate-change/ (accessed on 15 September 2021).

3. Crutzen, P.J.; Stoermer, E.F. The Anthropocene. IGBP Glob. Change Newsl. 2000, 41, 17-18. [CrossRef]

4. Jeffry, L.; Ong, M.Y.; Nomanbhay, S.; Mofijur, M.; Mubashir, M.; Show, P.L. Greenhouse gases utilization: A review. Fuel 2021, 301. [CrossRef]

5. Lewis, S.L.; Maslin, M.A. Defining the Anthropocene. Nature 2015, 519, 171-180. [CrossRef] [PubMed]

6. Wiedmann, T.; Lenzen, M.; Keyßer, L.T.; Steinberger, J.K. Scientists' warning on affluence. Nat. Commun. 2020, 11. [CrossRef]

7. Worland, J. The Pandemic Remade Every Corner of Society. Now It's the Climate's Turn. Available online: https: / /time.com/ magazine/us/5955224/april-26th-2021-vol-197-no-15-u-s/ (accessed on 18 September 2021).

8. United Nations Brundtland Report. Report of the World Commission on Environment and Development: Our Common Future. 1987. Available online: http:/ / www.undocuments.net/our-common-future.pdf (accessed on 1 September 2021).

9. United Nations Millennium Development Goals. Available online: https://www.undp.org/content/undp/en/home/ sdgoverview/mdg_goals.html (accessed on 18 September 2021).

10. Transforming Our World: The 2020 Agenda for Sustainable Development; United Nations General Assembly: New York, NY, USA, 2015.

11. UNESCO. UNESCO and Sustainable Development. Available online: http:// unesdoc.unesco.org/images/0013/001393/139369e. pdf (accessed on 20 June 2021). 
12. UNESCO. 15 Clues to Support the Education 2030 Agenda. Available online: https://unesdoc.unesco.org/ark:/48223/pf0000259 069 (accessed on 20 June 2021).

13. UNESCO. Education for Sustainable Development Goals: Learning Objective. 2017. Available online: https://unesdoc.unesco. org/ark:/48223/pf0000247444 (accessed on 20 June 2021).

14. Ball, S.J.; Maguire, M.; Braun, A. How Schools Do Policy: Policy Enactments in Secondary Schools; Routledge: London, UK, 2012. [CrossRef]

15. CID. Sport as a Tool for Sustainable Development. Conceptual Introduction and Review of Experiences; PART 1; Ibero-American Sports Council: Montevideo, Uruguay, 2019.

16. Commonwealth Secretariat. Measure the Contribution of Sport, Physical Education and Physical Activity to the Sustainable Development Goals; The Commonwealth: London, UK, 2019.

17. UNESCO. Kazan Action Plan. In Proceedings of the Sixth International Conference of Ministers and Senior Officials in Charge of Physical Education and Sports (MINEPS VI), Kazan, Russia, 13-15 July 2017.

18. Baena-Morales, S.; Jerez-Mayorga, D.; Delgado-Floody, P.; Martínez-Martínez, J. Sustainable Development Goals and Physical Education. A Proposal for Practice-Based Models. Int. J. Environ. Res. Public Health 2021, 18, 2129. [CrossRef]

19. Welch, R.; Taylor, N.; Gard, M. Environmental attunement in health, sport and physical education. Sport. Educ. Soc. 2021, 26, 339-348. [CrossRef]

20. Olive, R.; Enright, E. Sustainability in the Australian Health and Physical Education Curriculum: An ecofeminist analysis. Sport. Educ. Soc. 2021, 26, 389-402. [CrossRef]

21. Thorpe, H.; Brice, J.; Clark, M. New materialisms, sport and the environment: Imagining new lines of flight. Sport. Educ. Soc. 2021, 26, 363-377. [CrossRef]

22. Fernández-Balboa, J.M. Sociocultural characteristics of the hidden curriculum in physical education. Quest 1993, 45, 230-254 [CrossRef]

23. Anderson-Butcher, D. Youth Sport as a Vehicle for Social Development. Kinesiol. Rev. 2019, 8, 180-188. [CrossRef]

24. Linnér, S.; Larsson, L.; Gerdin, G.; Philpot, R.; Schenker, K.; Westlie, K.; Mordal Moen, K.; Smith, W. The enactment of social justice in HPE practice: How context(s) comes to matter. Sport. Educ. Soc. 2020. [CrossRef]

25. Eisenmann, J.C.; Wickel, E.E.; Welk, G.J.; Blair, S.N. Relationship between adolescent fitness and fatness and cardiovascular disease risk factors in adulthood: The Aerobics Center Longitudinal Study (ACLS). Am. Heart J. 2005, 149, 46-53. [CrossRef] [PubMed]

26. Henriksson, H.; Henriksson, P.; Tynelius, P.; Ekstedt, M.; Berglind, D.; Labayen, I.; Ruiz, J.R.; Lavie, C.J.; Ortega, F.B. Cardiorespiratory fitness, muscular strength, and obesity in adolescence and later chronic disability due to cardiovascular disease: A cohort study of 1 million men. Eur. Heart J. 2020, 41, 1503-1510. [CrossRef] [PubMed]

27. REDS. The SDGs in 100 Spanish Cities, 2nd ed.; REDS: Madrid, Spain, 2020. Available online: https://reds-sdsn.es/informe-odsciudades-2020 (accessed on 21 September 2021).

28. UNESCO. UN Decade of ESD. Available online: https://en.unesco.org/themes/education-sustainable-development/what-isesd/un-decade-of-esd (accessed on 21 September 2021).

29. UNESCO Quality Physical Education Policy Project. Available online: https:/ / en.unesco.org/themes/sport-and-anti-doping/ sports-education/qpe (accessed on 21 September 2021).

30. Lindsey, I.; Darby, P. Sport and the Sustainable Development Goals: Where is the policy coherence? Int. Rev. Sociol. Sport 2019, 54, 793-812. [CrossRef]

31. Lindsey, I.; Chapman, T. Enhancing the Contribution of Sport to the Sustainable Development Goals; Commonwealth Secretariat: London, UK, 2017.

32. Campillo-Sánchez, J.; Segarra-Vicens, E.; Morales-Baños, V.; Díaz-Suárez, A. Sport and Sustainable Development Goals in Spain. Sustainability 2021, 13, 3505. [CrossRef]

33. Lozano, A.; Figueredo, V. Los Objetivos de Desarrollo Sostenible en la formación de los futuros maestros: Uso de metodologías activas. Campo Abierto Rev. Educ. 2021, 4, 245-257. [CrossRef]

34. Bergman, B.G. Assessing impacts of locally designed environmental education projects on students' environmental attitudes, awareness, and intention to act. Environ. Educ. Res. 2016, 22, 480-503. [CrossRef]

35. Fremerey, C.; Bogner, F.X. Cognitive learning in authentic environments in relation to green attitude preferences. Stud. Educ. Eval. 2015, 44, 9-15. [CrossRef]

36. Hansmann, R.; Laurenti, R.; Mehdi, T.; Binder, C.R. Determinants of pro-environmental behavior: A comparison of university students and staff from diverse faculties at a Swiss University. J. Clean. Prod. 2020, 268, 121864. [CrossRef]

37. Sutton, S.G.; Gyuris, E. Optimizing the environmental attitudes inventory: Establishing a baseline of change in students' attitudes. Int. J. Sustain. High. Educ. 2015, 16, 16-33. [CrossRef]

38. Martín Ezpeleta, A.; Echegoyen Sanz, Y. Environmental attitudes in the literature classroom with preservice teachers. Profesorado 2020, 24, 184-202. [CrossRef]

39. Gericke, N.; Boeve-de Pauw, J.; Berglund, T.; Olsson, D. The Sustainability Consciousness Questionnaire: The theoretical development and empirical validation of an evaluation instrument for stakeholders working with sustainable development. Sustain. Dev. 2019, 27, 35-49. [CrossRef]

40. Domínguez, S. Magnitud del efecto, una guía rápida. Educ. Méd. 2017, 19, 251-254. [CrossRef] 
41. Cohen, J. Statistical Power Analysis for the Behavioral Sciences; Routledge: London, UK, 2013; ISBN 9781134742707.

42. Coolican, H. Research Methods and Statistics in Psychology. Res. Methods Stat. Psychol. 2018. [CrossRef]

43. Faul, F.; Erdfelder, E.; Lang, A.G.; Buchner, A. G*Power 3: A flexible statistical power analysis program for the social, behavioral, and biomedical sciences. Behav. Res. Methods 2007, 39, 175-191. [CrossRef] [PubMed]

44. Hopkins, W.; Marshall, S.; Batterham, A.; Hanin, J. Progressive statistics for studies in sports medicine and exercise science. Med. Sci. Sports Exerc. 2009, 41, 3-12.

45. Baena-Morales, S.; Merma Molina, G.; Gavilán-Martín, D. ¿Qué Conocen Los Profesores De Educación Física Sobre Los Objetivos De Desarrollo Sostenible? Un Estudio Cualitativo-Exploratorio (What Do Physical Education Teachers Know about the Sustainable Development Goals? A Qualitative-Exploratory Study). Retos 2021, 42, 452-463. [CrossRef]

46. Marcos-Merino, J.M.; Corbacho-Cuello, I.; Hernández-Barco, M. Analysis of sustainability knowingness, attitudes and behavior of a Spanish pre-service primary teachers sample. Sustainability 2020, 12, 7445. [CrossRef]

47. Cebrián, G.; Junyent, M. Competencies in education for sustainable development: Exploring the student teachers' views. Sustainability 2015, 7, 2768-2786. [CrossRef]

48. Ull, M.A.; Martínez-Agut, M.P.; Piñero, A.; Aznar-Minguet, P. Perceptions and Attitudes of Students of Teacher-training towards Environment and Sustainability. Procedia Soc. Behav. Sci. 2014, 131, 453-457. [CrossRef]

49. Olsson, D.; Gericke, N. The adolescent dip in students' sustainability consciousness - Implications for education for sustainable development. J. Environ. Educ. 2016, 47, 35-51. [CrossRef]

50. Tikka, P.M.; Kuitunen, M.T.; Tynys, S.M. Effects of educational background on students' attitudes, activity levels, and knowledge concerning the environment. J. Environ. Educ. 2000, 31, 12-19. [CrossRef]

51. Gifford, R.; Sussman, R. Environmental Attitudes. In The Oxford handbook of environmental and conservation psychology; Clayton, S., Ed.; Oxford University Press: Oxford, UK, 2012; pp. 65-80.

52. Bogner, F.X.; Wiseman, M. Outdoor Ecology Education and Pupils Environmental Perception in Preservation and Utilization. Sci. Educ. Int. 2004, 15, 27-48.

53. Larson, L.R.; Castleberry, S.B.; Green, G.T. Effects of an environmental education program on the environmental orientations of children from different gender, age, and ethnic groups. J. Park Recreat. Adm. 2010, 28, 95-113.

54. Levine, D.S.; Strube, M.J. Environmental attitudes, knowledge, intentions and behaviors among college students. J. Soc. Psychol. 2012, 152, 308-326. [CrossRef] [PubMed]

55. Liefländer, A.K.; Bogner, F.X. The effects of children's age and sex on acquiring pro-environmental attitudes through environmental education. J. Environ. Educ. 2014, 45, 105-117. [CrossRef]

56. Baena-Morales, S.; Martinez-Roig, R.; Hernádez-Amorós, M.J. Sustainability and Educational Technology-A Description of the Teaching Self-Concept. Sustainability 2020, 12, 309. [CrossRef] 